BNWL-SA--3160

DE93 009880

B A T TELLE B NORTHWEST BATTELLE MEMORIAL INSTITUTE PACIFIC NORTHWEST LABORATORIES
POST OFFICE BOX 999 RICHLAND. WASHINGTON 99352

TITLE AND AUTHOR

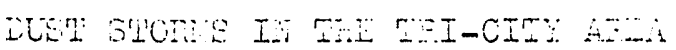

T.E. TEMIL

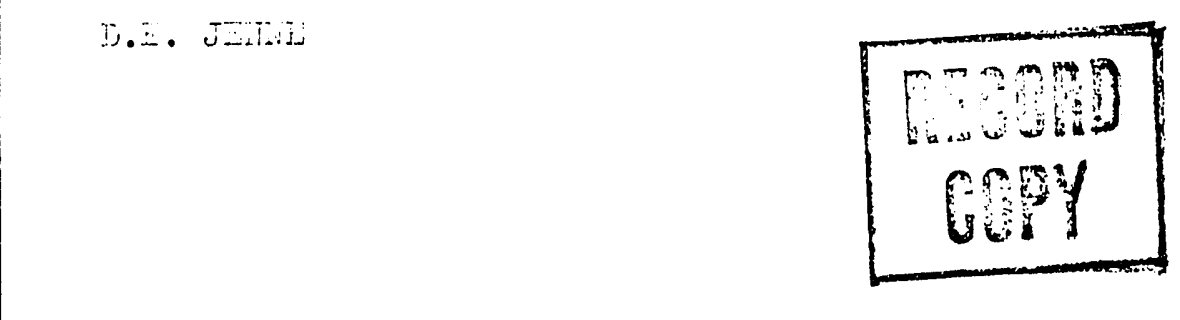

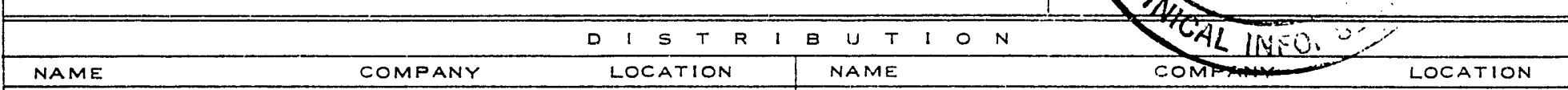

\begin{tabular}{|c|c|c|c|c|c|}
\hline \hline ROUTE TO & PAYROLLNO. & COMPANY & LOCATION & FILES ROUTE & SIGNATURE AND DATE \\
\hline & & & & & \\
\hline & & & & & \\
\hline & & & & & \\
\hline $54-1100-025$ (8-69) AEC.RL RICHLAND. WASH. & & & & \\
\hline
\end{tabular}


BNWL-SA-3160

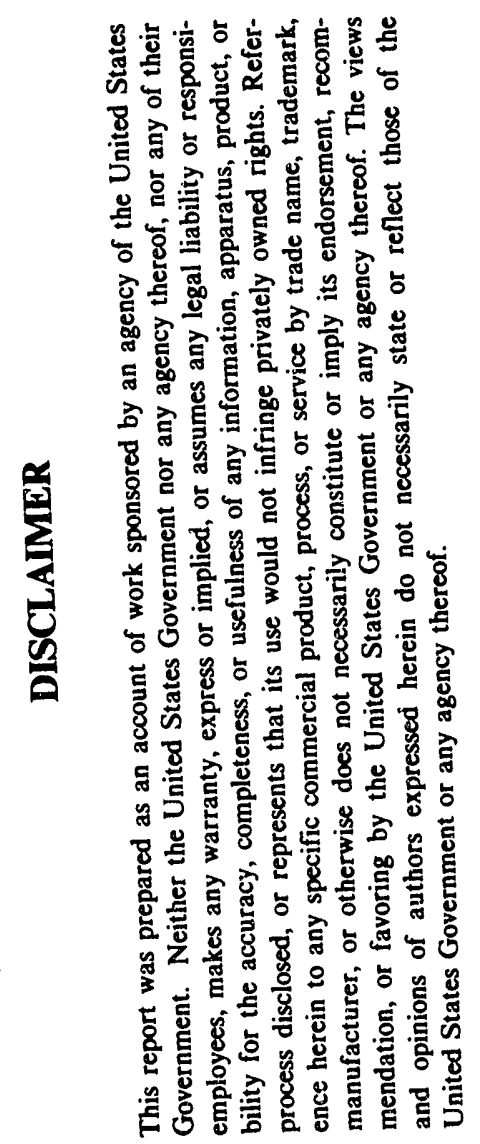

DUST STORMS IN THE TRI-CITY AREA (a)

D. E. Jenne

\begin{abstract}
Battelle Memorial Institute
Pacific Northwest Laboratory

Richland, Washington
\end{abstract}

March $1 \dot{9} 70$

Paper for oral presentation at the Washington Environmental

Council Luncheon, Pasco, Washington, March 21, 1970.

(a) This paper is based on work performed under United States Atomic Energy Commission Contract AT(45-1)-1830 
BNWL-SA-3160

\section{DUST STORMS IN THE TRI-CITY AREA}

The meteorologist recognizes two types of dust storms. To become part of a climatological record, each requires that airborne dust particles be sufficiently dense to restrict visibility to 6 miles or less. In one type (D), dust is carried in from a distance source. In the other (BD), dust is picked up and blown about locally. We experience both types in the Tri-Cities although approximately 7 of every 10 are the BO type. In this discussion, we will consider any observation of either $D$ or $B D$ to be a dust storm.

The Tri-City Area experiences an average of 6 dust storm days ner year. Three of these occur during the spring and one in each of the other seasons.

Half of all Tri-City dust storms occur with wind blowing from the SW. Another $25 \%$ occur with $W$ and $N W$ winds and $16 \%$ with $N$ and NE winds. This leaves only $9 \%$ from directions $E, S E$, and $S$. Wind speeds during dust storms have ranged from 60 down to as low as $4 \mathrm{mph}$. However, $19 \mathrm{mph}$ is the lowest speed yet observed during a type "BD" storm. In one extreme case of a type "D" storm, dust carried in from the Big Bend County north of here obscured the sky and reduced visibility to as little as $1 / 4$ mile. Yet, for five hours during this storm, average hourly wind speeds never exceeded $9 \mathrm{mph}$. 
BNWL-SA-3160

The average persistence of a Tri-City dust storm is about 3 hours, but may vary from less than 1 to more than 10 hours.

The primary cause of Tri-City dust storms is wind blowing over expanses of 1 and with no protective cover. Such areas occur on both dry land and irrigated farms. The degree of moisture in the top soil is relatively unimportant as dust storms may begin within a few hours after the end of a drenching rain.

Most of our dust storms originate in the Horseheaven Hills. This is because of the extensive dry land farming done in the hills and their geographical location with respect to the direction of our strongest winds (SW).

Severe dust storms also occur in irrigated sections of the Columbia Basin north of Pasco and the toll of their damage is considerable. Issues of the Tri-City Herald during March, 1967, pictured irrigation canals nearly filled with packed sand and reported that the South Columbia Basin Irrigation District assesses the average district farmer about $\$ 200$ per year for such damage. This does not include "Thousands of man-hours and costs that each devotes individually." $(\mathrm{TCH}, 3-15-67)$

Whether or not dust storms constitute a major source of air pollution in the area is debatable. However, they are repulsive to everybody and can cause allergic reactions in susceptible people. 
BNWL-SA-3160

Road closures resulting from poor visibility and clean-up jobs imposed on Tri-City housewives are other consequences of our dust storms.

Then there are subtle effects, such as loss of soil fertility and eventual depletion of hundreds of thousands of currently productive acres. In this context, dust storms are much more than a nuisance and fully deserve the attention of conservation-oriented organizations such as this. 
$\checkmark$
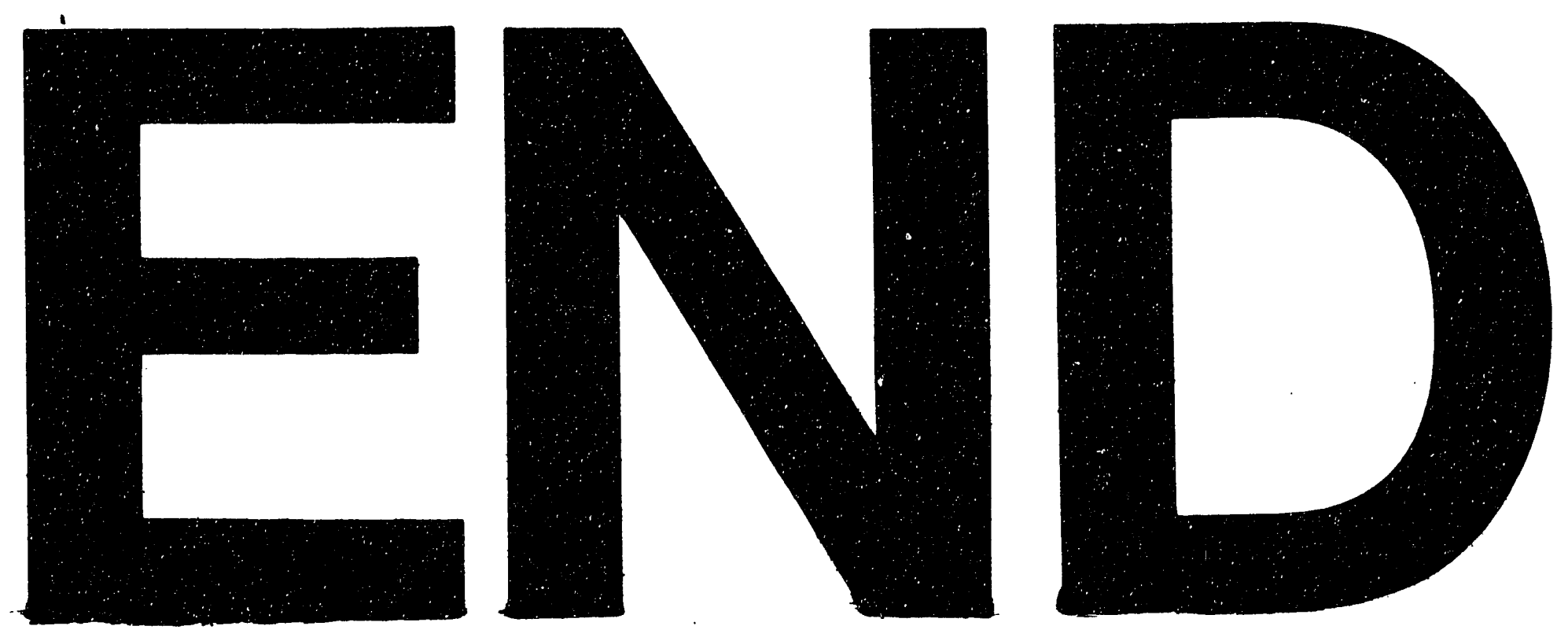

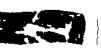
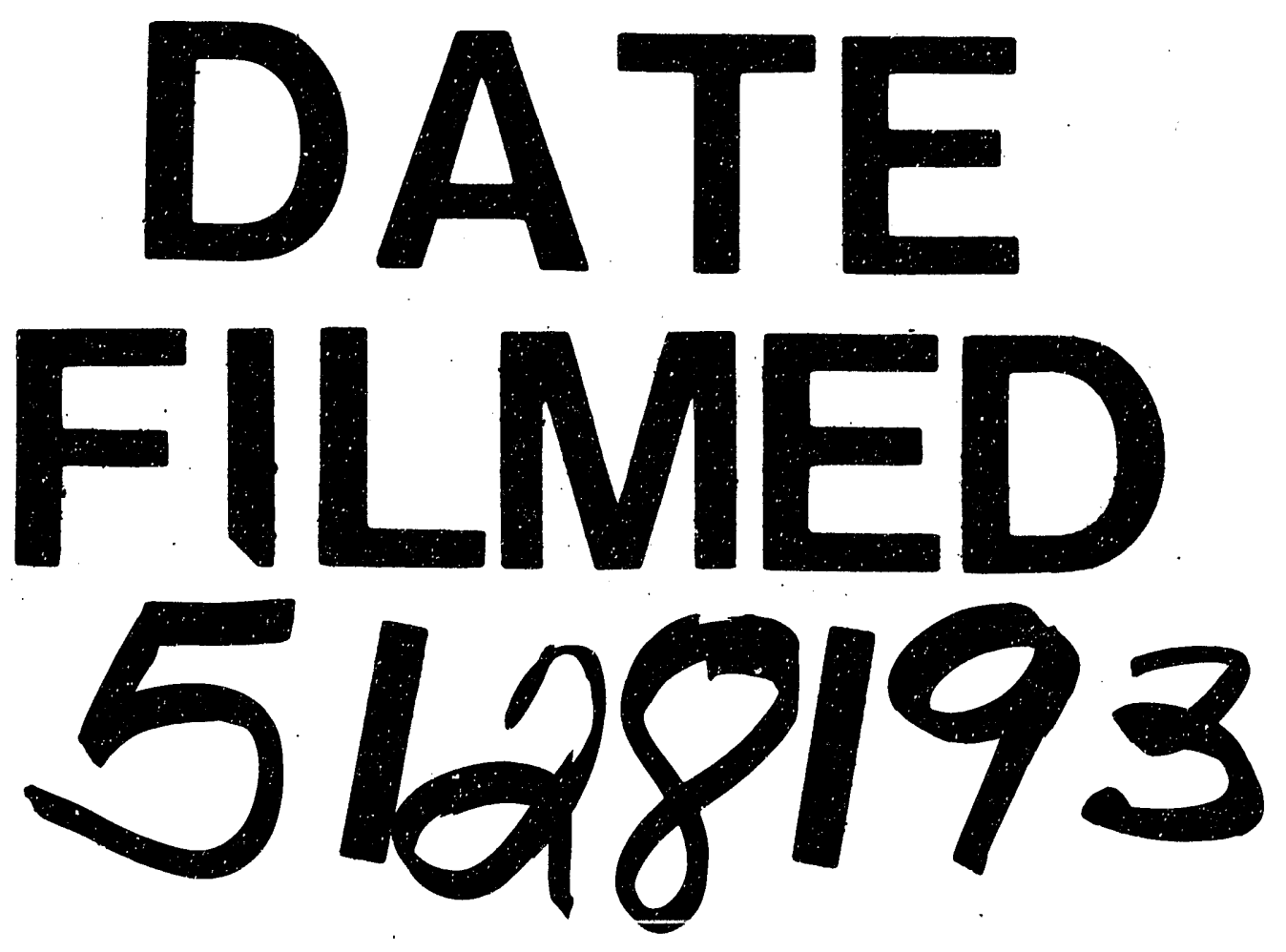
